Ciência eNatura, Santa Maria, v. 37 n. 4 set-dez 2015, p. 577-593

Revista do Centro de Ciências Naturais e Exatas - UFSM

ISSN impressa: 0100-8307 ISSN on-line: 2179-460X

\title{
ciênciaenatura
}

\section{Distribuição da Precipitação Pluviométrica no Período Veranil e Invernal de 2013/2014 na Área Urbana de Santa Maria/Rs e seu Entorno}

\author{
Distribution of Precipitation in the Veranil Period and wintry 2013/2014 in the urban area of \\ Santa Maria/Rs and its surroundings
}

\author{
Jakeline Baratto, Cássio Arthur Wollmann, Ismael Luiz Hoppe \\ Universidade Federal de Santa Maria, Departamento de Geociências - \\ Climatologia Geográfica, UFSM, RS, Brasil.
}

\section{Resumo}

O presente trabalho tem por objetivo analisar a distribuição da precipitação pluviométrica no período sazonal do verão de 2013/2014 e no inverno de 2014 na área urbana de Santa Maria/RS e seu entorno. Para o desenvolvimento deste trabalho foram construídos e colocados 10 pluviômetros artesanais em pontos estratégicos, elaborados conforme Milanesi; Galvani (2013), e mais o dado oficial da estação Meteorológica da Universidade Federal de Santa Maria/INMET. Na análise dos resultados pode-se observar que no período veranil os maiores totais pluviométricos foram localizados ao Norte e Nordeste da área urbana. Já ao Sul e Sudoeste da área urbana, os menores totais pluviométricos do período sazonal citado. No periodo invernal pode-se observar que os maiores totais pluviométricos foram localizados ao Norte da área urbana, próximos ao P07 na Fundação Moã e nos bairros Chácara das Flores. Já os menores totais localizaram-se ao Sul e Sudoeste da área de estudo. Dessa forma, se pode observar que a distribuição espaço-temporal pluviométrica na área urbana de Santa Maria e seu entorno são influenciadas por dois fatores: deslocamento de Frentes Polares e a influência do relevo, ainda que não seja significativa

Palavras-chave: Climatologia1, precipitação2, variabilidade espaço- temporal3, Santa Maria4.

\section{Abstract}

This paper concerns in to analyze the rainfall distribution in the seasonal period of summer of 2013/2014 and in the winter of 2014 on the urban area of Santa Maria/RS and its surroundings. For the development of this paper 10 rain gauges were built and installed in strategic points, elaborated according to Milanesi; Galvani (2013), plus the official weather station of the University Federal of Santa Maria/INMET. In the analysis of the results it can be observed that in the summer period the higher total pluviometric were localized at North and Northeast of the urban area. at South and Southwest of the urban area has the smaller total pluviometric of the seasonal period of summer. In the winter period it can be observed that the higher total pluviometric were localized at North of the urban area, next to P07 in Fundação Moã and in the neighborhoods of Chácara das Flores. Already the smaller total pluviometric are located at South and Southeast of the field of study. Thereby the pluviometric spatial-temporal distribution in the urban area of Santa Maria and its surroundings are influenced by two factors. One is the displacement of the polar fronts and the other is the relief, although it is not significant, most cases.here

Keywords: Climatology1, precipitation2, spatial-temporal variability3, Santa Maria4 


\section{Introdução}

$\mathrm{A}$ variabilidade climática afeta de forma direta e indireta a vida econômica e social da população, como na geração de energia, nas atividades agrícolas, na indústria turística, entre outros. Um dos fenômenos físicos decorrentes dessa variabilidade climática é a precipitação pluvial, que constitui um importante fator no controle do ciclo hidrológico e pode ser considerada uma das variáveis atmosféricas de maior influência na qualidade do meio ambiente. Dessa forma, as quantidades relativas de precipitação pluvial, ou seja no seu volume, seu regime e as intensidades de chuvas são algumas das suas características que afetam a população, a economia e o meio ambiente (Britto, et al. 2006).

Assim, na determinação da variação espacial das precipitações pluviométricas, há a possibilidade de minimizar, com maior segurança, os riscos ambientais provenientes de eventos "extremos", como inundações ou períodos de estiagem. Sendo assim, na análise espacial das precipitações pluviométricas, a orografia constitui-se um elemento importante na avaliação das diferentes médias de chuvas (Silveira, 2012).

Conhecer a variabilidade temporal e a distribuição pluviométrica de uma cidade, ou seu entorno próximo, pode auxiliar o município em futuros projetos que possam minimizar os impactos socioeconômicos e ambientais decorrentes de estiagem ou inundações. A precipitação, tanto em seu excesso como a sua falta, causam problemas para a economia, para o meio ambiente e para a sua população.

A área urbana, que é o foco do estudo, os principais problemas referentes a precipitação pluviométrica são os alagamentos de ruas e o extravasamento de córregos, canalizados ou não. Porém é bom frisar que esse não é um problema com o excesso de chuva, mas sim com a impermeabilização do solo, ou com a falta de um sistema coletor de águas pluviais adequado. Porém, os eventos de precipitação extrema podem aumentar esse problema que é muito comum nas médias e grandes cidades brasileiras.
Assim sendo, conhecer a variação do regime pluviométrico, e em quais áreas da cidade ocorrem os maiores totais pluviométricos poderá ajudar o município a sanar em parte esses problemas. Dessa forma, a pluviosidade é condicionada principalmente pela dinâmica atmosférica, e o relevo, promove a distribuição espacial da mesma. Para AYOADE (2003) as montanhas, sozinhas, não são capazes de reter toda a umidade que contém a massa de ar que se desloca por ela, mas elas recebem mais precipitação do que em terrenos mais baixos. Para o autor a grande influência da montanha na precipitação depende do seu tamanho e do alinhamento relativo aos ventos que portam chuvas.

Nesse contexto geográfico, a precipitação pluvial é um dos elementos climáticos que possuem maior impacto, pois está relacionado com diversos setores da sociedade, de forma que o regime pluviométrico pode afetar a economia, o meio ambiente e a própria sociedade. A chuva é um elemento importante na compreensão do clima em escala regional e pode ser considerado o principal elemento na análise e organização do planejamento territorial e ambiental (Correa, 2013).

Para GALVANI; LIMA (2012) além da distribuição regional da precipitação pluviométrica deve-se ser considerado a distribuição temporal, pois o planejamento de atividades agrícolas e atividades econômicas de determinada região pode depender em função da distribuição sazonal das chuvas. Ainda, a precipitação destaca-se pela sua grande variabilidade temporal e espacial, tanto no período de ocorrência, quanto na intensidade. Assim, muitas vezes podem acarretar consequências negativas em diversos setores da sociedade como acontece durante períodos longos de estiagem e ou em períodos com chuvas intensas e ou vários dias de chuvas consecutivos, que podem levar às inundações e erosões no solo (Paula, 2008).

Para AYOADE (2003) a precipitação se refere as várias formas líquidas e congeladas de água, como por exemplo, neve, granizo, orvalho, geada, nevoeiro. Dessa forma, a chuva é umas 
das três formas de precipitação, e ocorre quando a Umidade Relativa do Ar (URA) está saturada, atingindo, teoricamente, $100 \%$ na atmosfera, e atinge gravitacionalmente a superfície terrestre e ocorre sob a forma líquida ou pluvial (chuva) e sob a forma sólida (granizo e neve) (Paula, 2009). Para essa pesquisa foi adotado o termo precipitação referente a chuva na forma líquida, por ser historicamente a forma mais representativa deste fenômeno na área de estudo.

Por fim, MENDONÇA e DANNI-OLIVEIRA (2007) destacam que a precipitação pluvial é a quantidade total de água que precipita em um dia, e assim, a partir do total diário obtém-se os totais mensal, sazonal e o anual. A precipitação é dada em milímetros e refere à água coletada em pluviômetro ou pluviógrafo.

No Rio Grande do Sul são poucos trabalhos que evidenciam a influência orográfica na distribuição da precipitação pluviométrica. Dessa forma, podemos destacar FORGIARINI, et al. (2013) que estudou na região central do Rio Grande do Sul o efeito orográfico da precipitação pluviométrica. Assim, os autores utilizaram o município de Silveira Martins como foco de estudo, pois é vizinho do município de Santa Maria, e também por estar localizado no limite da Depressão Central e o Planalto Meridional Riograndense. Os referidos autores, fizeram o monitoramento das chuvas com a instalação de dez postos pluviométricos, sendo, quatro postos a barlavento e seis a sotavento de Silveira Martins.

O monitoramento realizado pelos autores ocorreu no ano hidrológico de 2011/2012, assim como resultados eles tiveram um nível de significância de 5\%, dessa forma, na análise estatística sugere a ocorrência de efeito orográfico. Os autores também tiveram como resultado, que nos eventos de precipitação o efeito orográfico se intensifica, na região, na $s$ chuvas frontais decorrentes do movimento das massas de ar polares, no sentido principal sudoeste-nordeste (Fiorgiani, et al. 2013).

Outro autor que se deteve a analisar a distribuição da precipitação pluviométrica foi MILANESI (2007) onde se propôs avaliar as diferenças pluviométricas nas vertentes continental e oceânica da Ilha de São Sebastião (Ilhabela - SP) para validação da ocorrência do efeito orográfico. Assim, o autor instalou um conjunto de treze pluviômetros experimentais ao longo da Estrada de Castelhanos. Com os dados dos totais mensais, obtidos no ano hidrológico 2004/2005, o referido autor correlacionou também com outros postos pluviométricos da região, às altitudes diversas e à atuação das correntes de sudeste predominando na.

Os resultados obtidos pelo autor apontam para o relevo como responsável por interferir no ritmo pluvial da região, claramente diferenciado na ilha e na distribuição espacial da chuva local. Assim, a vertente continental apresenta, em média, 20\% menos chuva que a vertente oceânica a barlavento, o que caracteriza a sombra de chuva. $O$ autor, também verificou que na vertente oceânica, ocorreu a intensificação e aumento das quantidades de chuva a partir dos $300 \mathrm{~m}$ de altitude. O total mensal máximo foi observado pelo estudo foi a $600 \mathrm{~m}$ de altitude (708,5mm, em março/2005). Também foi calculado pelo referido autor o gradiente pluviométrico em função do relevo que apresenta, em média, o acréscimo de $2,5 \mathrm{~mm}$ de chuva a cada metro de altitude (Milanesi, 2007).

Outro autor podemos destacar que analisou a distribuição da precipitação pluviométrica é CORREA (2013) que analisou a da distribuição espacial e variabilidade da precipitação pluviométrica na bacia do rio Piquiri-PR, baseando-se na teoria sistêmica e nas condições de troca de energia e matéria em uma bacia hidrográfica. Assim, o referido autor analisou a precipitação para o período de 1976-2010 com dados de 73 postos pluviométricos do Instituto das Águas do Paraná.

Assim, o autor verificou a distribuição e a variabilidade espaço-temporal da precipitação pluviométrica através dos mapas de isoietas gerados a partir da interpolação dos dados pluviométricos na bacia do rio Piquiri. O referido autor conclui que os sistemas atmosféricos e o relevo participam ativamente na distribuição anual, sazonal e mensal da precipitação. Dessa forma, entre as cotas altimétricas de 400 a 900 metros o efeito do relevo potencializa o acréscimo de precipitação média anual, indicando singularidades no que diz respeito à variabilidade espacial da chuva (Correa, 2013). 
1.1 Localização da Área de estudo

O município de Santa Maria se encontra na região central do Rio Grande do Sul, cuja a área é de $1.788,121 \mathrm{~km}^{2}$, e sua área urbana corresponde a $7,07 \%$. Está situada entre as coordenadas geográficas $29^{\circ} 23^{\prime}$ a $30^{\circ} 00^{\prime}$ de latitude Sul e de $53^{\circ} 15^{\prime}$ a $54^{\circ} 00^{\prime}$ de longitude Oeste. A população de Santa Maria, segundo o Censo de 2010 é de 261.031 habitantes, sendo que a maior parte da população reside na área urbana, correspondendo a 95\% (IBGE, 2014). Na figura 01 é possível observar a área de estudo.

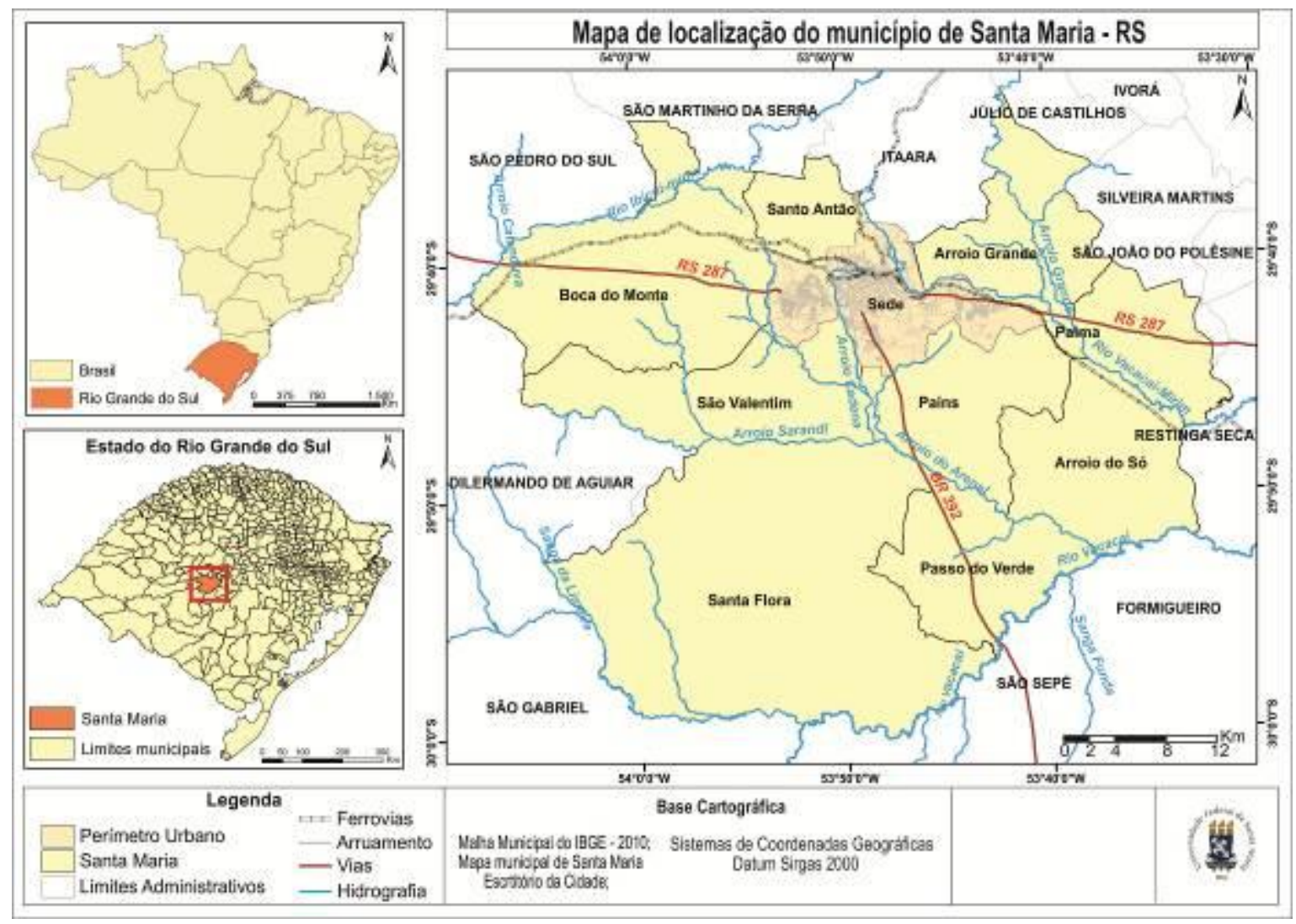

Figura 01: Localização da área de Estudo.

Santa Maria tem uma precipitação pluvial bem distribuída ao longo de todo o ano, pois a cidade se encontra, segundo Köppen (1931) no Clima Subtropical Úmido com verões quentes (Cfa), sendo C - clima temperado chuvoso e quente; $f$ - nenhuma estação seca; a - verão quente e mês mais quente com temperatura média maior do que $22^{\circ} \mathrm{C}$ e a do mês mais frio superior a $3^{\circ} \mathrm{C}$. Assim o município não apresenta estação seca.

Em uma perspectiva da climatologia dinâmica, Sartori (2003) coloca que a localização zona de transição, do Rio Grande do Sul, em reflete a participação de Sistemas Atmosféricos (massas e frentes polares) e de Intertropicais (massas tropicais e correntes perturbadas), porem os primeiros exercem o controle dos tipos de tempo em $90 \%$ dos dias do anos e também proporcionam a distribuição mensal e anual das chuvas.

A autora, em seus estudos salientou que a distribuição espacial das chuvas em todo o Rio Grande do Sul é essencialmente frontal, dessa forma é resultante da circulação atmosférica regional que é determinado pelo avanço periódico das massas polares durante todo o ano.

Da mesma maneira, a variação espacial da chuva sofre, em parte, a influência do relevo, já que o estado possui a Serra Geral no seu setor central, com alinhamento perpendicular à direção geral de deslocamento das frentes polares, que é principalmente de Sudoeste para Nordeste (SW $\Rightarrow$ NE) desde o extremo Sul do 
Oceano Pacífico até as latitudes tropicais do Oceano Atlântico, o que determina alterações no volume pluviométrico registrado nas regiões climáticas estado. (Ibid, p. 28).
Dessa forma, de acordo com a figura 2 é possível observar que a precipitação pluviométrica média anual para área de estudo é de entorno de $1700 \mathrm{~mm}$ a $1800 \mathrm{~mm}$.

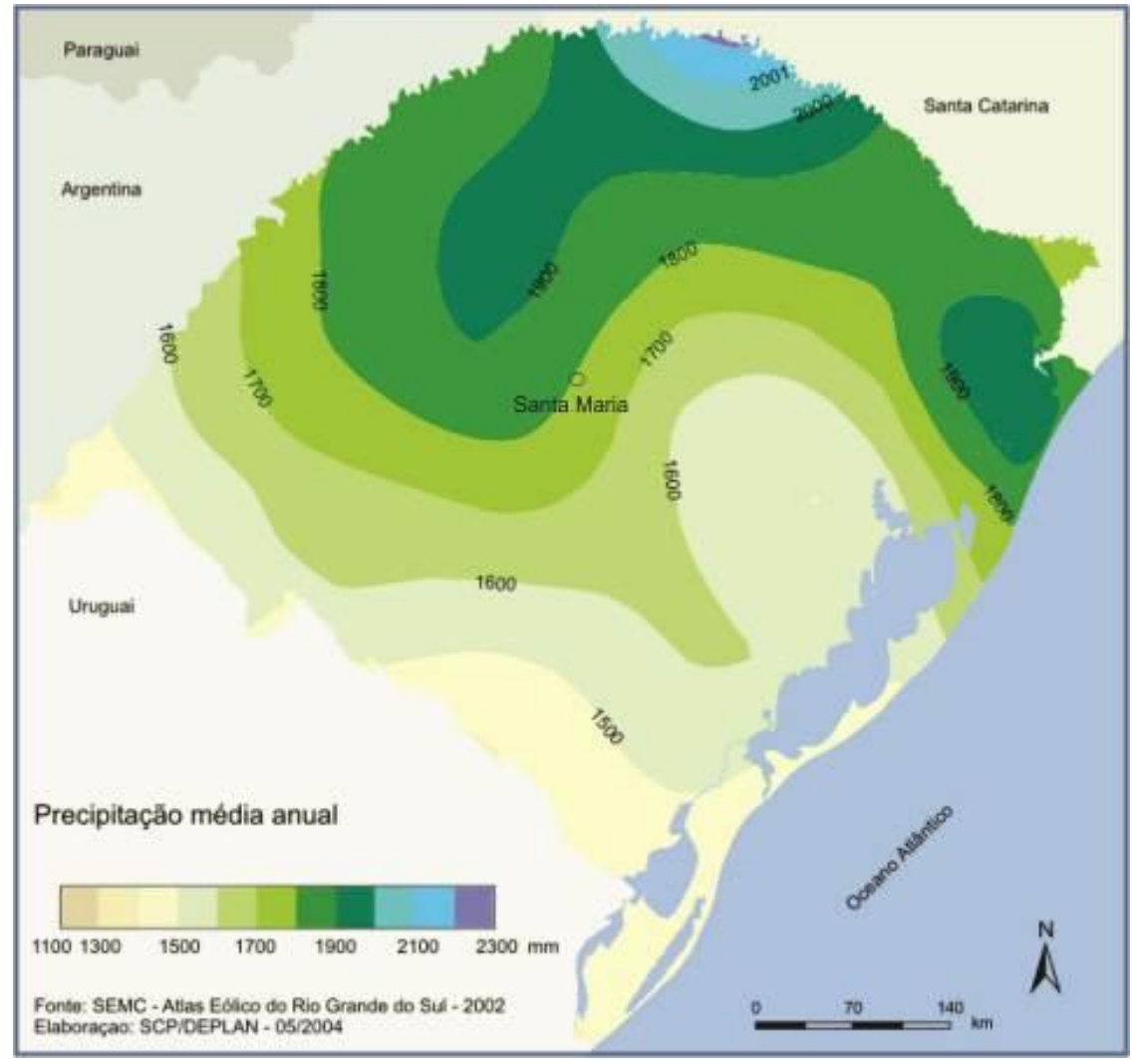

Figura 02 : Distribuição da Precipitação pluviométrica no RS. Fonte: SENC, 2002.

Conforme DAL' ASTRA (2009) a amplitude altimétrica, da área urbana de Santa Maria, é de 372 metros, estando o ponto mais elevado da cidade a 432 metros acima do nível do mar, na porção Norte da área urbana, no topo do Morro das Antenas, e o ponto de menor altitude é de 60 metros, localizado no extremo Sul da área urbana, junto ao Arroio Passo das Tropas. A autora também salienta que aproximadamente

$\mathrm{Na}$ caracterização do verão e do inverno no Rio Grande do Sul, especialmente a região central podemos destacar os trabalhos publicados por Sartori (1993a; 2003) e Wollmann; Sartori (2009).

No verão na Região Central do Rio Grande do Sul, que corresponde entre 22 de dezembro a 20 de março, a participação da Massa Polar Velha (MPV) é maior e domina em média mais de $45 \%$ dos dias da estação. A Frente Polar Atlântica (FPA) aparece em segundo lugar no número de dias sob seu domínio, totalizando
$85 \%$ da área urbana, encontra-se em altitudes inferiores a 150 metros, onde o relevo é característico da Depressão Periférica.

Já, na porção Norte da área de estudo, correspondente ao Rebordo do Planalto, as cotas altimétricas vão se sucedendo rapidamente, evidenciando um relevo de alta declividade, fortemente dissecado, cujas maiores altitudes ultrapassam os 400 metros (Dal' Astra, 2009). assim $20 \%$ dos dias de verão, assim também são incluídas as situações nas quais há deslocamento normal (sem oscilações do eixo frontal), como as ciclogêneses, afetando diretamente a região ou como frente estacionária (Sartori, 2003).

Ainda a autora, coloca que a Massa Polar Atlântica (MPA) típica tem participação em cerca de $19 \%$ dos dias, mas domina na região por apenas um ou dois dias enquanto diminuem as temperaturas, a MPA domina logo após a passagem da Frente Polar, pois ela entra rapidamente em processo de 
tropicalização devido à maior insolação e também é maior a radiação solar absorvida pela superfície continental. Dessa forma, caracteriza o verão, elevando às temperaturas máximas e mínimas gradativa. Às vezes na retaguarda da frente se desloca um ar polar descaracterizado pelas condições de aquecimento do continente o que provoca a maior frequência da MPV.

Entre os Sistemas Intertropicais que atuam no verão, a Massa Tropical Atlântica (MTA), e a Massa Tropical Continental são as que têm maior participação na circulação atmosférica regional, dominando em cerca de $5 \%$ dos dias cada uma. Esses sistemas prevalecem na região somente nas fases pré-frontais em substituição à $\mathrm{MPV}$, devido à fusão que ocorre entre o Anticiclone Polar Atlântico (APA) e o Anticiclone Tropical Atlântico (ATA), gerando um único centro de alta pressão (Sartori, 2003).

Também há atuação das Instabilidades Tropicais ou de Noroeste e de Calhas Induzidas no verão, com cerca de $7 \%$ e $5 \%$ dos dias, respectivamente, e associadas às fases pré-frontais independentes da massa de ar que está dominando (Sartori, 2003).

De madeira geral, essas correntes perturbadas de circulação secundária provocam chuvas fortes e rápidas, tempestades e precipitações de granizo localizados, se caracterizando pela presença de nuvens cumulonimbus $(\mathrm{Cb})$, de grande desenvolvimento vertical, geradas por convecção térmica que é resultante do intenso aquecimento do interior do continente durante o verão (Sartori, 2003).

WOLLMANN; SARTORI (2009) distinguem os verões do Rio Grande do Sul em três casos típicos, sendo eles: verão habitual, verão chuvoso e verão menos chuvoso. No verão habitual, que corresponde os anos de 1986 (dezembro) e 1987 (janeiro e fevereiro), se caracteriza como habitual, pois a pluviometria se encontra dentro do normal para o Estado. No verão mais chuvoso que corresponde os anos de 1997/1998 estava sofre a influência de el Niño, assim elevando os índices pluviométricos Já no verão menos chuvoso (2004/2005) teve uma redução nos totais pluviométricos em função da La Niña.

Para o inverno, de 21 de junho a 21 de setembro (93 dias), a MPA típica, atua em 60\% da participação geral dos Sistemas Atmosféricos devido à intensificação do Anticiclone Polar Atlântico. As altas pressões de origem polar tornam-se mais intensas, devido a diminuição geral das temperaturas, fazendo com que a MPA permaneça por até oito (8) dias consecutivos, e muitas vezes não chega a tropicalizar-se devido a aproximação de nova FPA. A MPV reduz sua frequência em relação ao verão e outono, passando a dominar em cerca de $11 \%$ do total de dias do inverno (Sartori, 2003).

A participação de FPA é maior no inverno (22\% dos dias) com aumento dos casos de frentes estacionárias e de ciclogêneses (formação de ciclones frontais), situações atmosféricas responsáveis pelos grandes índices pluviométricos que podem ocorrer no inverno. $\mathrm{O}$ aumento de perturbações no eixo frontal deve-se, em parte, ao deslocamento do ATA mais para o continente nessa época do ano, opondo-se ao APA e, consequentemente, dificultando o avanço normal da FPA (Sartori, 2003).

A MTA domina em $6 \%$ do total de dias do inverno e substitui a MPV nas fases préfrontais. A Massa Tropical Continental tem participação menor em função do retraimento latitudinal da Baixa do Chaco mais para o Norte. As Correntes Perturbadas (Instabilidades Tropicais e Calhas Induzidas) controlam cerca de $3 \%$ dos dias e são responsáveis pelas chuvas e/ou granizo que antecedem a FPA (Sartori, 2003).

Dessa forma, o presente trabalho teve por objetivo principal analisar a distribuição da precipitação pluviométrica no período sazonal do verão de 2013/2014 e no inverno de 2014 na área urbana de Santa Maria/RS e seu entorno próximo.

\section{Materiais e Métodos}

Inicialmente procurou-se em bibliografias existentes experiências na utilização de pluviômetros artesanais para que se pudesse compreender melhor a sua construção, utilização e confiabilidade em pesquisas científicas. Assim, pluviômetros foram construídos conforme propõe MILANESI; GALVANI (2003). Nesse contexto, foram construídos os pluviômetros com os seguintes 
materiais: canos de PVC $100 \mathrm{~mm}$ com 1,50 metros de altura, duas tampas plásticas para cada cano, funis de plástico para a captação da precipitação pluviométrica com $16 \mathrm{~cm}$ de diâmetro. Para a montagem dos pluviômetros foi necessário apenas o encaixe do funil em uma das tampas. Na figura 3 é possível observar os pluviômetros artesanais instalados a campos.

Foram utilizados os pluviômetros artesanais, pois eles são uma alternativa econômica que auxiliam trabalhos que abordam os estudos pluviométricos, pois ainda hoje as redes de Estações Meteorológicas oficiais são escassas em lugares remotos, algumas vezes longe de grandes centros urbanos. Dessa forma, o pluviômetro artesanal é economicamente viável para a utilização em lugares onde não possuem rede de estação oficial e pouca mão de obra especializada para a manutenção dos mesmos, tornando-se assim um instrumento econômico e duradouro.

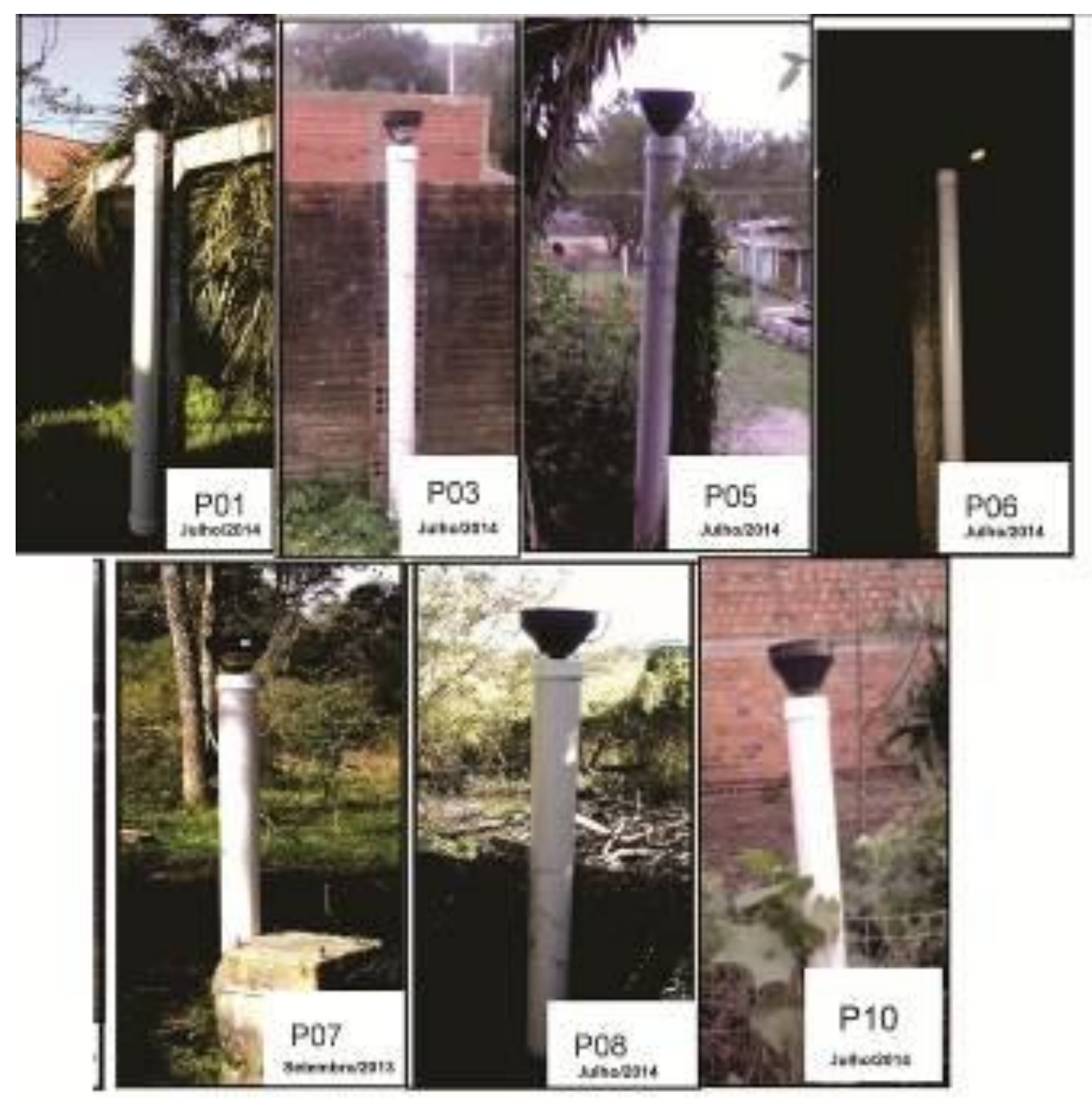

Figura 03: Pluviômetros artesanais instalados. Fonte: Trabalhos de Campos

Foram selecionados para a instalação dos pluviômetros 10 locais diferentes: Loteamento Novo Horizonte no Bairro Camobi (P01), no Bairro São José (P02), no Bairro Nossa Senhora do Perpétuo Socorro (P03), no Bairro Chácara das Flores (P04), no Bairro Passo da Areia (P05), no Bairro Nossa Senhora de Fátima (P06), na Reserva Particular do Patrimônio Natural (RPPN) da Fundação Mo'ã (P07), no Bairro Tancredo Neves (P08), no Bairro de Camobi
(P10), e no Bairro Km três (P11). No Bairro de Camobi foi coletado ainda a precipitação na Estação Meteorológica da Universidade Federal de Santa Maria (P09).

Foi instalado um pluviômetro na RPPN da Fundação Mo'ã, que está localizado no município de Itaara, ao norte de Santa Maria devido ao fato de estar a uma altitude considerável, com vista à observação do efeito do rebordo e também por estar longe de possíveis 
ataques de vândalos que implicaria na deficiência da pesquisa.

Os pluviômetros foram instalados sempre obedecendo às normas da Organização Meteorológica Mundial (OMM) para assim garantir a maior confiabilidade dos dados.
(DAEE- Departamento de Águas e Energia Elétrica, 2000).

Assim, na Figura 04 é possível observar a distribuição dos 10 pluviômetros instalados, além da estação Meteorológica do UFSM/INMET na área urbana de Santa Maria e seu entorno.

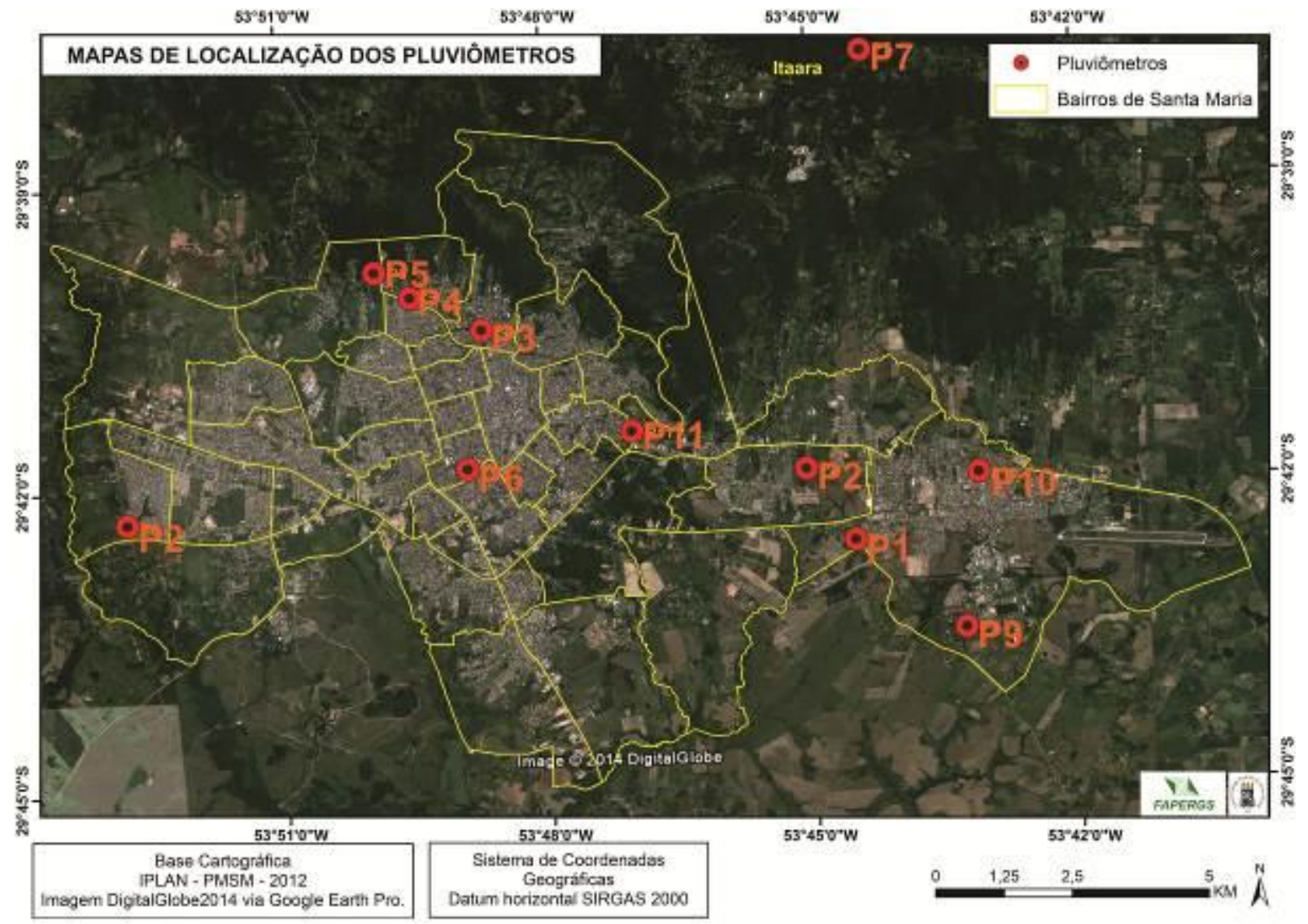

Figura 04: Localização dos Pluviômetros Instalados e a Estação da INMET. Fonte: Google Earth Pro.

Junto com as instalações dos pluviômetros foram coletados os dados da altitude e das coordenadas UTM de cada ponto. O primeiro período de coleta correspondendo aos meses dezembro/2013, janeiro/2014 e fevereiro/2014 do verão, e junho, julho e agosto de 2014 correspondente ao inverno para a segunda coleta.

Após a obtenção dos dados da precipitação dos 11 pluviômetros, os mesmos foram manipulados em tabelas no Excel versão 2013. Para a confecção dos mapas da distribuição pluviométrica no período do verão e do inverno da área urbana de Santa Maria foi necessária a criação da tabela contendo os dados de cada pluviômetro mais sua localização e altitude. Assim, para identificar a distribuição espacial das precipitações pluviométricas foi utilizado o
O cálculo para transformar os litros coletados no pluviômetro experimental foi realizado com base na fórmula $V=\pi R^{2} h$, onde $V$ é o volume coletado, $\pi$ é a constante, $R^{2}$ é o raio do funil e $h$ é a altura da chuva (Milanesi e Galvani, 2012). Assim cada litro de água coletada equivale a 48,4 mm conforme aponta HOPPE (2015).

programa computacional Surfer 8.0 para a criação das isoietas e posteriormente foi feita a construção do banco de dados e a edição final no software ArcGIS 9.3.

\section{Resultados e Discussão}

No período em análise da pesquisa, no verão 2013/2014 o mês de dezembro de 2013 o ponto em que teve a maior precipitação pluviométrica 
foi no P10 com 109,9 mm a uma altitude de 94 m. Já o ponto em que teve uma menor precipitação pluviométrica foi no P03 que teve uma precipitação de $12,1 \mathrm{~mm}$ a uma altitude de $106 \mathrm{~m}$. A precipitação pluvial média para o mês de dezembro foi de $74,7 \mathrm{~mm}$.

No mês em análise totalizou-se 9 dias com chuva com base nos dados da Estação Meteorológica da UFSM. Para o mês de dezembro os registos mostram que a precipitação ficou abaixo da normal climatológica de 1961-1990 que é de 150,0 mm, comparando o total pluviométrico mensal da Estação INMET localizada no bairro Camobi que para o mês foi de $92,8 \mathrm{~mm}$. Assim a precipitação para Santa Maria ficou 38,2\% abaixo da normal climatológica.

Para o mês de janeiro de 2014 o ponto em que teve o maior total pluviométrico foi $o$ localizado no P03 com uma a precipitação pluviométrica de $278,2 \mathrm{~mm}$, o ponto possui uma altitude de $106 \mathrm{~m}$. Para o mês o ponto em que teve a menor precipitação foi o P02 com a precipitação de $96,8 \mathrm{~mm}$ e uma altitude de 112 m. A média para o mês de outubro foi de 161,0 $\mathrm{mm}$. Esse mês teve um total de 15 dias com chuva.
Assim, para o mês em análise comparando com a normal climatológica de 1961-1990, que é de $160,0 \mathrm{~mm}$, com o dado mensal total da Estação INMET (132,3 mm), se pode notar que a precipitação foi abaixo da normal. Assim, a precipitação para o mês de janeiro ficou 17,3\% abaixo da normal climatológica de 1961-1990.

Para o mês de fevereiro de 2014 o ponto em que teve a maior precipitação pluviométrica total foi o P02, com 242,0mm, e está localizado a uma altitude de $112 \mathrm{~m}$. O P10 teve a menor precipitação com 106,5 mm e sua altitude é de $129 \mathrm{~m}$. Para o mês em analise, que teve 11 dias com precipitação pluviométrica, registrou-se uma média de precipitação entre os pontos coletados de 150,5 mm.

Comparando-se o dado da Estação INMET com a normal pode-se notar que a precipitação pluviométrica foi abaixo do normal, esperado assim para o mês de fevereiro o P09 (Estação INMET) teve uma precipitação de $108,6 \mathrm{~mm}$ e a normal climatológica de 1961- 1990 foi de 130,0 $\mathrm{mm}$. A precipitação para o mês de fevereiro, Santa Maira teve a precipitação $16,5 \%$ abaixo da referida normal. Na figura 5 é possível observar os dados de cada pontos nos meses referente ao período veranil. 


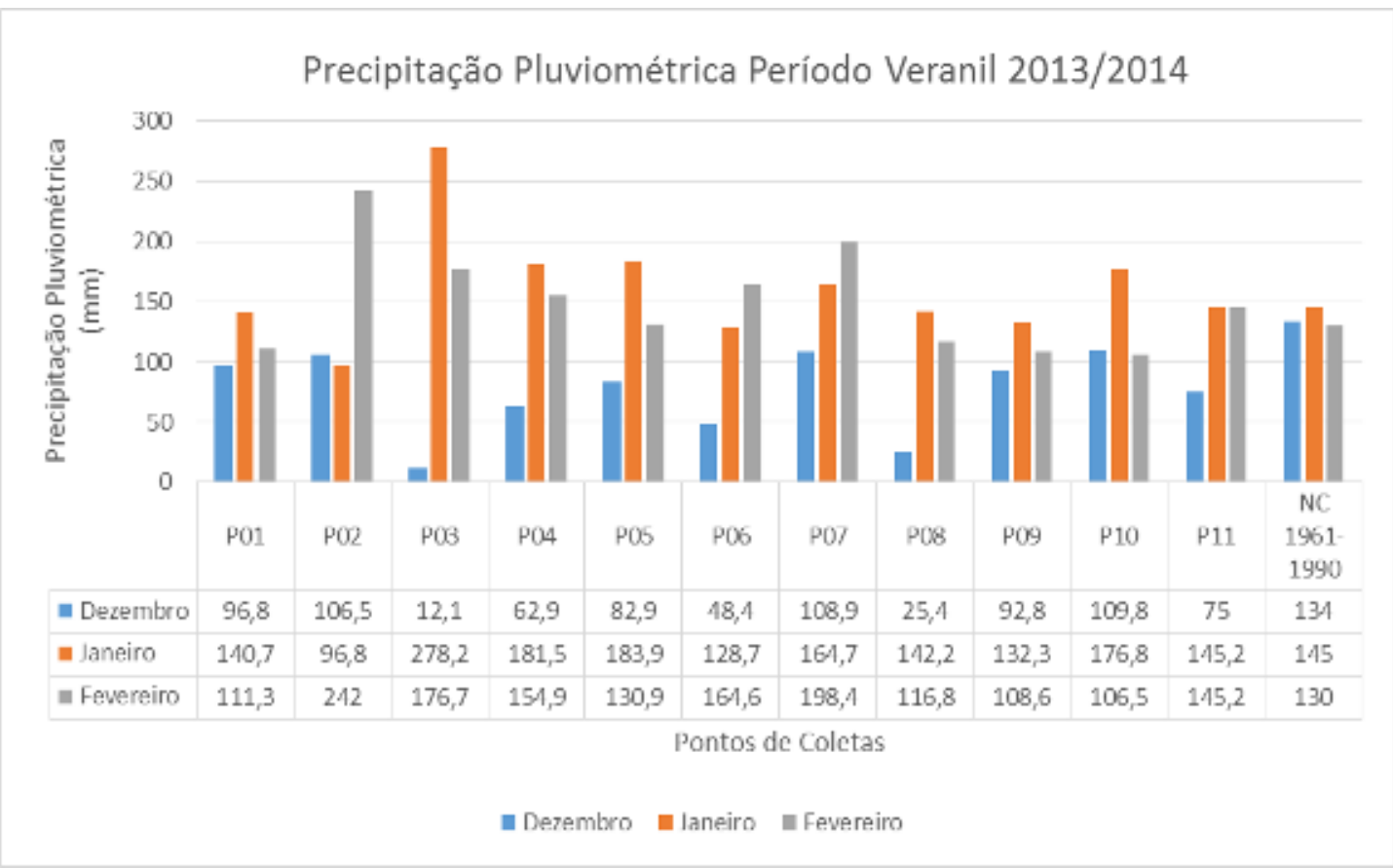

Figura 05: Precipitação Pluviométrica total mensal do período veranil. Fontes: Trabalhos de campo e UFSM/INMET.

No período sazonal do verão a média do total acumulado para o período entre todos os pontos foi de $386,2 \mathrm{~mm}$. O P07 com 467,0 mm foi o ponto que teve o maior total pluviométrico para o período localizado na Fundação Mo'ã a uma altitude de $210 \mathrm{~m}$. O ponto de menor total pluviométrico foi o P08 com 284,4 mm localizado no bairro Tancredo Neves. A diferença entre os pontos de maior e menor precipitação foi de $187,6 \mathrm{~mm}$. Assim, para o período sazonal do verão teve 35 dias com precipitação. Como pode ser visto na figura 06 apenas 4 pontos ficaram abaixo da média para o período veranil.

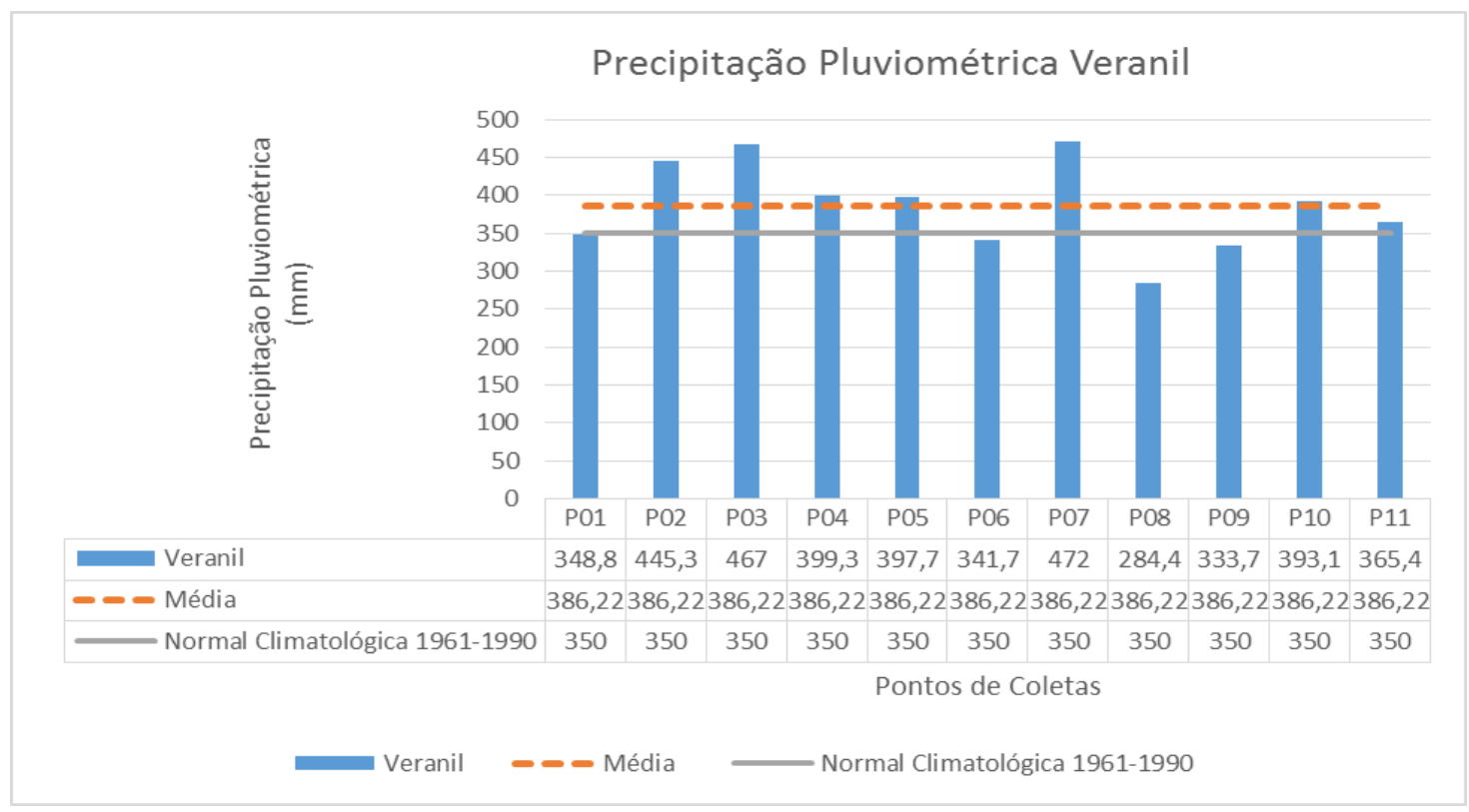

Figura 06 : Gráfico da precipitação pluviométrica total no período veranil e invernal nos pontos de coletas. Fonte: Trabalhos de Campos, 2013/2014 e INMET, 2013/2014. 
Na figura 06 é possível observar que apenas os pontos P02, P03 e P07 ficaram acima da média dos pontos e da Normal Climatológica. E os pontos P06, P08 e P09 ficaram abaixo de ambas variáveis. O restantes dos pontos ficaram entre a Normal e a média dos pontos.

No mapa do período veranil pode-se observar que os maiores totais pluviométricos foram localizados a Norte e Nordeste da área urbana. Assim os bairros que tiveram os maiores totais foram N.S. Perpétuo Socorro, Itararé, Campestre do Menino Deus, Pé de Plátano e São José. Já ao Sul e Sudoeste da área urbana há os menores totais pluviométrico do período sazonal do verão. Os bairros que se localizam nessa área e tiveram os menores totais são Lorenzi, Boi Morto e Tancredo Neves Conforme pode ser visto na figura 07 


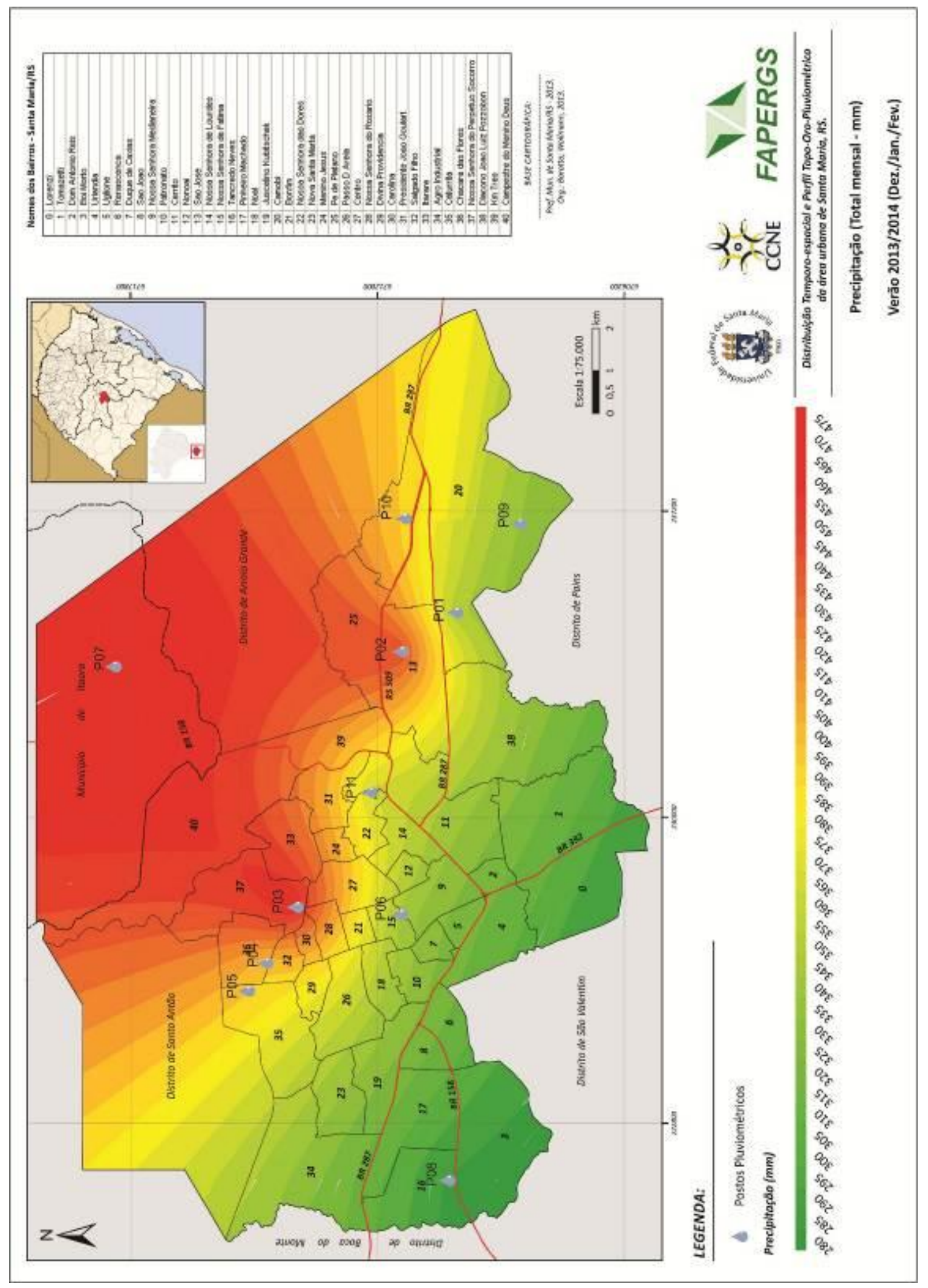

Figura 07: Precipitação Pluviométrica total mensal do período veranil. Fontes: Trabalhos de campo e UFSM/INMET. 
No período invernal, para o mês de junho de 2014 o ponto que registrou-se a maior precipitação pluviométrica foi o P04 (363,6 mm) cuja a altitude é de $140 \mathrm{~m}$. Já o ponto em que teve uma menor precipitação pluviométrica para o mês de junho foi no P07 que teve uma precipitação $237,2 \mathrm{~m}$ a uma altitude de $210 \mathrm{~m}$.

A precipitação média para o mês de junho foi de $297,5 \mathrm{~mm}$. No mês em análise totalizaram-se 13 dias com chuva. Para o mês de junho os registos mostraram que a precipitação ficou acima da normal climatológica de 1961-1990 considerando o dado coletado na Estação INMET. Segundo o dado disponível pela INMET a mês teve uma precipitação de $287,9 \mathrm{~mm}$, e a normal é de 140 $\mathrm{mm}$. Dessa forma, a precipitação ficou $102 \%$ acima da normal climatológica.

Para o mês de julho de 2014 três postos registraram os maiores totais pluviométricos: 285,6 mm, sendo eles, P08, P05 e P04, tendo uma altitude de $89 \mathrm{~m}, 180 \mathrm{~m}$ e $140 \mathrm{~m}$ respectivamente. Já o ponto em que teve a menor precipitação pra o mês de julho foi o P03 com a precipitação de $210,5 \mathrm{~mm}$ e uma altitude de $106 \mathrm{~m}$. No mês ocorreram 9 dias com precipitação pluviométrica. Assim, a média para o mês de julho foi de $263,2 \mathrm{~mm}$.
No mês de julho, comparando com a normal climatológica o dado da Estação INMET que foi de $255,2 \mathrm{~mm}$ para esse mês se pode notar que a precipitação foi acima da normal $(145,0 \mathrm{~mm})$. Assim o mês teve a precipitação $76 \%$ acima da normal climatológica.

A precipitação pluviométrica para o mês de agosto de 2014 teve o ponto de maior precipitação o P03 com 164,6 mm. Já o ponto de menor precipitação foi o P05 com um total de $67,7 \mathrm{~mm}$. No mês de agosto a média entre os pontos foi de 100,4 mm. Para o mês de agosto tiveram 13 dias com chuva.

Comparando a precipitação da Estação INMET para o mês de agosto com a normal climatológica 1961- 1990 pode-se notar que para o mês a precipitação ficou acima da normal. Assim para o mês de agosto o P09 teve uma precipitação de $196,5 \mathrm{~mm}$ já a média histórica para o mês é de aproximadamente $143 \mathrm{~mm}$. Dessa forma, a precipitação ficou $32 \%$ acima da normal.

$\mathrm{Na}$ figura 08 é possível observar a precipitação pluviométrica nos meses referentes ao período do inverno.

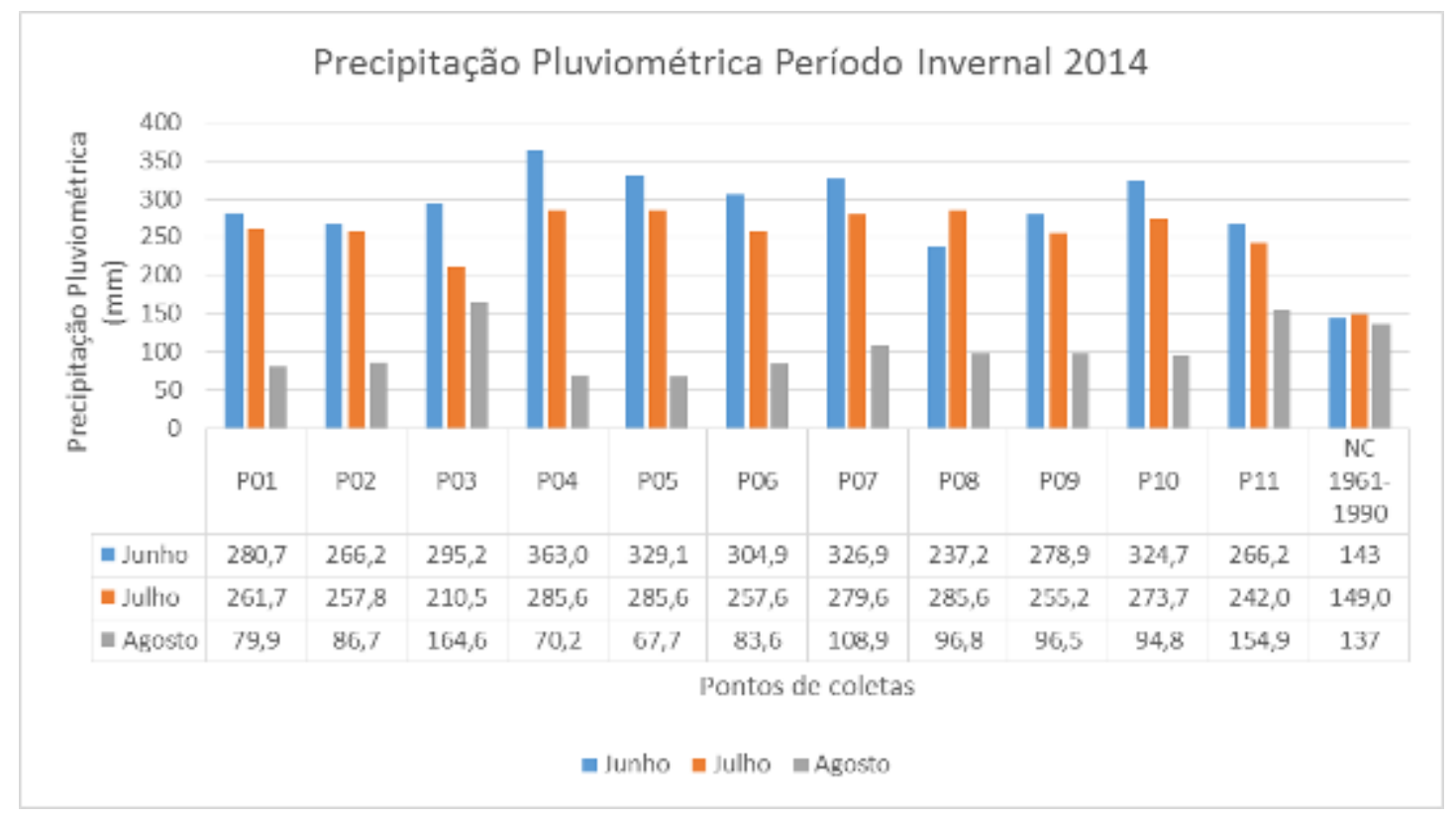

Figura 08: Precipitação Pluviométrica total mensal do período invernal. Fontes: Trabalhos de campo e UFSM/INMET. 
No período sazonal do Inverno a média total acumulado para o período entre os pontos foi de $661,1 \mathrm{~mm}$. O P04 foi o ponto que teve o maior total pluviométrico para o período de 718,8 $\mathrm{mm}$. Já o P02 com 610,7 mm foi o ponto com o menor total pluviométrico. Assim, para o período invernal ocorreram 35 dias com precipitação com todos os pontos acima da médias para o inverno (Figura 09).

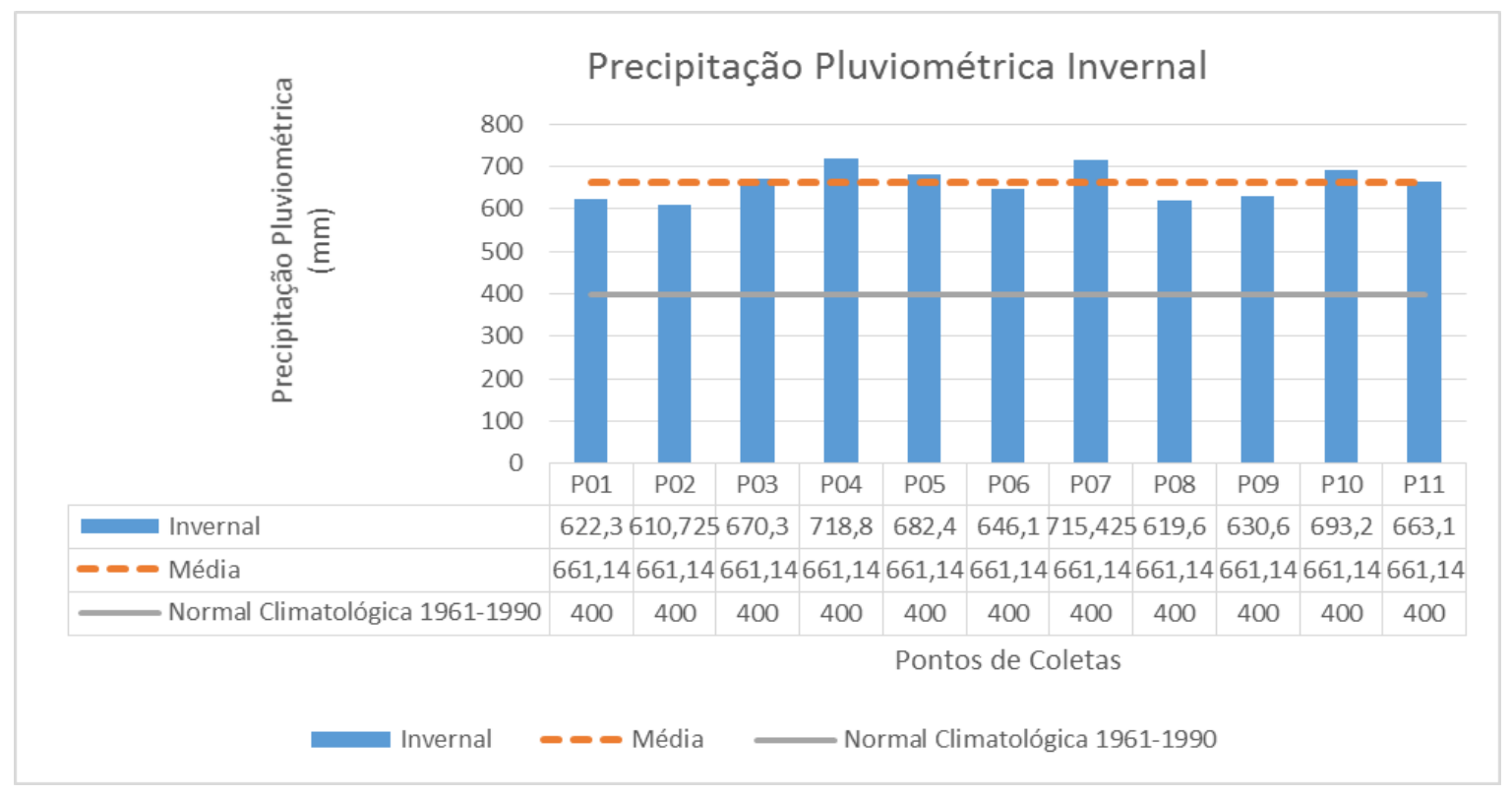

Figura 09: Precipitação Pluviométrica total mensal do período invernal Fontes: Trabalhos de campo e UFSM/INMET.

Na figura 09 é possível observar que todos os pontos em análise ficaram acima da Normal Climatológica 1961-1990. Apenas quatro ficaram acima da média de todos os pontos, sendo eles, o P04, P05, P07 e P10.

No mapa do período invernal pode-se observar que no período do inverno os maiores totais pluviométricos foram localizados ao
Norte da área urbana, próximos ao P07 na Fundação Mo'ã e nos bairros Charara das Flores, Campestre do Menino Deus, Salgado Filho. Já ao Sul e Sudoeste da área de estudo, os menores totais pluviométrico do período. Os bairros que se localizam nessa área e tiveram os menores totais são Trancredo Neves, Boi Morto, Lorenzi e Tomazetti, conforme a figura 10. 


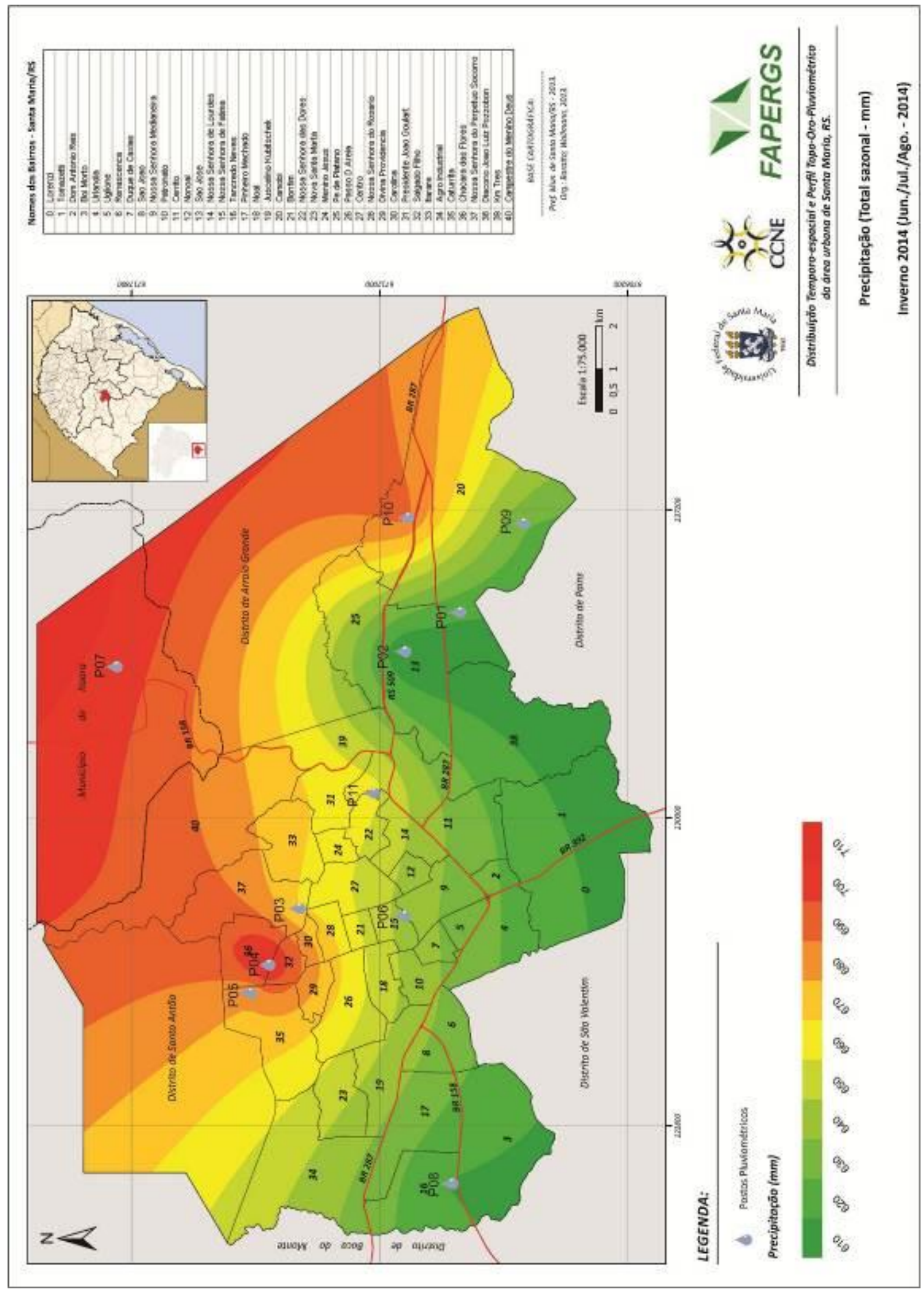

Figura 10: Precipitação Pluviométrica total mensal do período veranil. Fontes: Trabalhos de campo e UFSM/INMET 


\section{Considerações Finais}

$\mathrm{Na}$ análise da distribuição espacial da precipitação pluviométrica no período veranil e invernal 2013/2014 pode-se observar que para o verão o P07 localizado no Fundação Mo'ã teve a maior precipitação. O ponto que teve a menor precipitação total foi o P08 que está localizado no bairro Tancredo Neves para o mesmo período. Para o inverno o ponto de maior precipitação foi o P04 que está localizado no bairro Chácara das Flores. O ponto de menor precipitação pluviométrica total para o inverno foi o mesmo que para o verão (P08).

Para o período veranil o mês em que teve a maior média entre todos os pontos foi o mês de janeiro com uma precipitação de 161,0 $\mathrm{mm}$. Para o período invernal o mês que teve a maior média em junho com 297,0 mm.

Dessa forma, nos períodos em análise os bairros de Santa Maria localizados ao Norte e Nordeste tiveram os maiores totais pluviométricos, sendo eles, Chácara das Flores, Nossa Senhora do Perpétuo Socorro e Campestre do Menino Deus e também o bairro Camobi. Já os bairros localizados a Sudoeste e Sul da área urbana de Santa Maria, tiveram as menores precipitações totais para o período analisado, sendo eles, Boi Morto, São José, Lorenzi Trancredo Neves e Dom Antônio Reis.

Com a análise desses dois períodos sazonais pode-se observar que a distribuição da precipitação pluviométrica na área urbana de Santa Maria e seu entorno se estabeleceu conforme o relevo e o deslocamento dos sistemas frontais produtores de chuva. Dessa forma, a precipitação não se estabelece de forma uniforme, mas conforme os dois fatores geográficos.

Dessa forma, ao analisar em termos de planejamento da área urbana doo município, os bairros localizados ao norte e nordeste necessitam maior atenção em caso de eventos extremos de precipitação.

\section{Agradecimentos}

Deixo aqui o agradecimento a Fundação Mo'ã por disponibilizar a sua Reserva particular do patrimônio natural/RPPN para a instalação do pluviômetro e pelo auxílio nas saídas de campo até ao local para a coleta dos dados e a Fundação de Apoio à Pesquisa do Estado do Rio Grande do Sul/ FAPERGS por financiar este projeto.

\section{Referências}

AYOADE, J. O. Introdução a Climatologia para os Trópicos. 10. ed. Rio de Janeiro: Bertrand Brasil, 2002.

BRITTO, F. P.; BORLETTA, R.; MENDONÇA, M. Regionalização sazonal e mensal da precipitação pluvial máxima no estado do Rio Grande do Sul. Revista Brasileira de Climatologia, Vol. 2, p. 35-51, dez. 2006.

CORREA, M. G. G. Distribuição espacial e variabilidade da precipitação pluviométrica na bacia do rio Piquiri-PR. Dissertação (Mestre em Geografia Física) -Faculdade de Filosofia, Letras e Ciências Humanas da Universidade de São Paulo, São Paulo, 2013.

DAL'ASTA, A. P. Elaboração de Zoneamento Geoambiental para o Perímetro Urbano de Santa Maria - Rs. 2009. 176 f. Dissertação (Mestre em Geografia) - Universidade Federal de Santa Maria, Santa Maria, 2009.

FORGIARINI, et al. Análise De Chuvas Orográficas No Centro Do Estado Do Rio Grande Do Sul. Revista Brasileira de Climatologia. Ano 9 - Vol. 13 - JUL/DEZ 2013.

GALVANI, E. (Org.); LIMA, N. G. B. de (Org.). Climatologia Aplicada: Resgate aos estudos caso. 1. ed. Curitiba: Editora CRV, 2012. v. 1. $192 \mathrm{p}$.

HOPPE I.L, et al. Comparação Entre Um Abrigo Meteorológico De Baixo Custo e a Estação Meteorológica Oficial Do Inmet em Santa Maria (RS). Ciência\&Natura. Santa Maria, v. 37 Ed. Especial SIC, 2015, p. 132 - 137.

\section{IBGE - INSTITUTO BRASILEIRO DE GEOGRAFIA E ESTATÍSTICA. IBGE Cidade. Disponível em: $<$ http://www.cidades.ibge.gov.br/xtras/perfil .php?lang=\&codmun=430637\&search=rio-}


grande-do-sul I dilermando-deaguiar | infograficos:-informacoes-completas> Acesso em 04 de jul. 2014.

KÖEPPEN, W. Climatología. México - Buenos Aires: Fondo de Cultura Económica. 2oㅜ edição. 1931.

PAULA, G. M. de. O fenômeno El Niño Oscilação Sul e a Erosividade das Chuvas em Santa Maria, RS. 2009. 55f. Dissertação (Pós-Graduação Em Engenharia Agrícola) Universidade Federal de Santa Maria. 2009.

PAULA, A. D, de. A Relação entre o Vento Norte e a Precipitação Pluviométrica de 2001 a 2007 no Município de Santa Maria-RS. 2008, 67 f. Trabalho de Graduação II (Graduação em Geografia) Universidade Federal de Santa Maria, Santa Maria, 2008.

MENDONÇA, F.; DANNI-OLIVEIRA, I. M. Climatologia: Noções básicas e climas do Brasil. Oficina de Textos: São Paulo, 2009.

MILANESI, M. A. Avaliação do Efeito Orográfico na Pluviometria nas Vertentes Opostas da Ilha de São Sebastião (IlhabelaSP). 2007. 141 f. Dissertação (Mestrado em Geografia) - Faculdade de Filosofia, Letras e Ciências Humanas da Universidade de São Paulo, São Paulo, 2007.

MILANESI, M. A.; GALVANI, E. Pluviômetro Experimental Para Localidades Remotas. In.: Climatologia Aplicada: Resgate aos Estudos de Caso. Galvani, E.; Lima, N. G. B. (Orgs.). Curitiba: Editora CRV, 2012. v. 1. 192 p. 1 ed.

SARTORI, M. da G. B. A dinâmica do clima no Rio Grande do Sul: indução empírica e conhecimentos científicos. Terra Livre, São Paulo, Ano 19, vol. I, n. 20, p. 27-49,jan./jul. 2003.

Distribuição das Chuvas no Rio Grande do Sul e Variabilidade Temporo-Espacial no
Período 1912-1924. Anais,... Simpósio de Geografia Física, V, São Paulo. p. 275- 280, 1993b.

As Variações Pluviométricas e o Regime das Chuvas na Região Central do Rio Grande do Sul. Boletim de Geografia Teorética, 23 (45-46): 70-84, 1993c.

. A dinâmica do clima no Rio Grande do

Sul: indução empírica e conhecimentos científicos. Terra Livre, São Paulo, Ano 19, vol. I, n. 20, p. 27-49,jan./jul. 2003.

Gênese E Características do Vento Norte Regional em Santa Maria, Rs. . Anais,.... X Simpósio Brasileiro De Geografia Física aplicada, Rio de Janeiro, RJ. 2003. Disponível em:

http://www.cibergeo.org/XSBGFA/eixo3/3.4/ 146/146.htm >. Acesso em: 30 maio. 2014.

SECRETARIA DE RECURSOS HÍDRICOS, SANEAMENTO E OBRAS / DEPARTAMENTO DE ÁGUAS E ENERGIA ELÉTRICA CENTRO TECNOLÓGICO DE HIDRÁULICA E RECURSOS HÍDRICOS. Prefeitura de São Paulo. Rede de monitoramento pluviométrico da Prefeitura Municipal de São Paulo. São Paulo, 2000 Disponível em: $<$ http://www.daee.sp.gov.br>. Aceso em: 24 mar. 2013.

SILVEIRA, P. da C. Precipitação pluviométrica na Bacia Hidrográfica do Rio Vacacaí, RS. 2012. 56 f. Dissertação (Mestrado em Geográfica) - Universidade Federal de Santa Maria, Santa Maria, 2012.

WOLLMANN, C. A., SARTORI, M. da G. B. O Clima Do Rio Grande Do Sul No Verão: Análise Sobre A Circulação Atmosférica Regional E Os Principais Tipos De Sucessão Do Tempo Em Três Casos Típicos. Geografia: Ensino \& Pesquisa, Santa Maria, v. 13 n. 1, p. 3342, 2009a. 